\title{
Physical Basis of Quasi-optimal Seismoacoustic Pulse Generating for Geophysical Prospecting in Shallow Water and Transit Zones. Part 2. The Layout of Aqueous Seismic Source and the Results of Experiments
}

\author{
Danil S. Kudinov* \\ Oleg A. Maykov ${ }^{\dagger}$ \\ Siberian Federal University \\ Krasnoyarsk, Russian Federation \\ Pavel V. Balandin $\ddagger$ \\ LLC Evenkiyageofizika \\ Tyumen, Russian Federation
}

Received 09.09.2019, received in revised form 03.11.2019, accepted 20.12.2019

\begin{abstract}
The article discusses theoretical aspects of seismic wave excitation of in the aquatic environment, addresses the problems of instrumental implementation of a fundamentally new source of seismic vibrations that can work: in the water area, in tidal and coastal zones. The scientific substantiation of the developed seismic source (SS) design is given.

The results of the seismic influence simulation of hydrodynamic resistance on the media, as well as the formation of the "added mass" are given. The results were obtained using the developed mathematical model of the motion of the radiating surface. Based on the experimental work, a comparative analysis of the energy efficiency of the developed seismic source model and the serial sample of the VEM-50 "Yenisei" water seismic source was made. Experimental results were obtained at the geophysical well of the test and training area.
\end{abstract}

Keywords: seismic source, seismoacoustics, pseudorandom sequence, scrambling sequence, shallow water, transit zone.

Citation: D.S.Kudinov, O.A.Maykov, P.V.Balandin, Physical Basis of Quasi-optimal Seismoacoustic Pulse Generating for Geophysical Prospecting in Shallow Water and Transit Zones. Part 2. The Layout of Aqueous Seismic Source and the Results of Experiments, J. Sib. Fed. Univ. Math. Phys., 2020, $13(1), 71-78$.

DOI: $10.17516 / 1997-1397-2020-13-1-71-78$.

\section{Rationale of aqueous seismic source structure}

To conduct investigational studies of effective excitation of seismic vibrations in an aqueous medium. The experimental model of electromagnetic seismic source (EMSS) was created. There is the short-stroke electromagnetic drive inside the outrigger float is loaded on the reaction mass

\footnotetext{
*kudinovdanil@yandex.ru

${ }^{\dagger}$ maykov_oleg@bk.ru

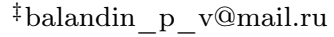

(c) Siberian Federal University. All rights reserved
} 
of the outrigger float $M$ and forces on outrigger buttom, which is radiator seismic vibrations. The 3D model of EMSS is shown in Fig. 1.

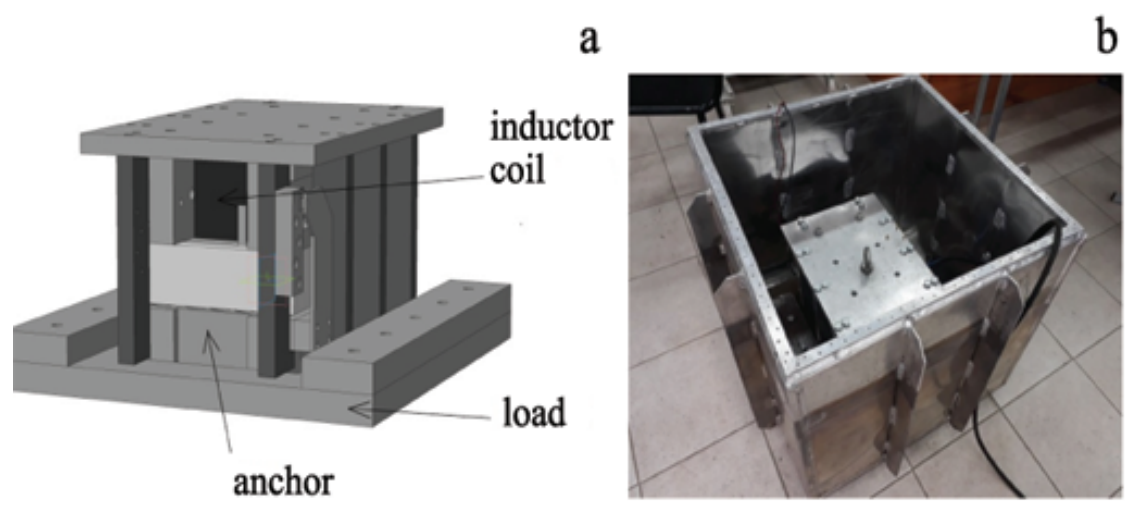

Fig. 1. The EMSS model for water areas: $\mathrm{a}-3 \mathrm{D}$ model; $\mathrm{b}-$ physical configuration of experimental model and outrigger float

The initial data are set based on the required characteristics of the EMSS. Let us conduct an estimated calculation of the design parameters of the seismic source:

- electromagnetic traction force, $F_{E M}=25000 \mathrm{~N}$;

- the magnetic gap between the anchor and inductor, $\delta=4 \mathrm{~mm}$;

- current impulse time, $\tau=3 \mathrm{~ms}$;

- power-supply voltage of energizing coil, $U=1200 \mathrm{~V}$.

The magnetic core is made of electrical steel, which provides maximum value of induction $B=2 \mathrm{~T}$, then the magnetic force in the core $H_{s t}=150 \mathrm{~A} / \mathrm{m}$. The steel grade selection is based on need for ensure maximum value of induction of a magnetic field $B$ when the magnetizing force is the least [3]. The required cross section of the magnet core is determined by the electromagnet traction force $F_{E M}=25 \mathrm{kN}$ :

$$
S_{M C}=\frac{F_{E M} \cdot \mu}{B^{2}}=78.5 \cdot 10^{-4} m^{2} .
$$

We use a square magnetic core for the inductor with dimensions of $9 \times 9=0.81 \mathrm{~m}^{2}$. The field line length of the magnet core $l=0.6 \mathrm{~m}$. The required magnetization current is determined by the formula [1]:

$$
I=I_{M C}+I_{\delta}=H_{s t} \cdot l+B \frac{2 \delta}{\mu_{0}}=12890 A,
$$

where $I_{M C}$ is magnetization current of magnetic core; $I_{\delta}$ is magnetization current of the magnetic gap.

The voltage of the magnetizing coil is determined by the formula [1]:

$$
U_{L}=B \cdot n \cdot S_{M C} / \tau_{C P},
$$

where $n$ is number of turns in the magnetizing coil; $\tau_{C P}$ is magnetization current pulse duration. 
The limit numbers of turns $n$ for the area of magnetic core in case of $S_{M C}=0.0081 \mathrm{~m}^{2}$ and $\tau_{C P}=1 \mathrm{~ms}$ is determined by setting a maximum allowable voltage $U_{L}=1200 \mathrm{~V}$. It is determined from the formula (3).

$$
n=\frac{U_{L} \cdot \tau_{C P}}{B \cdot S_{M C}}=74 .
$$

The inductance of the inductor magnetizing coil $L$ is determined by the formula:

$$
L=\frac{1,26 \cdot 10^{-6} \cdot n^{2} \cdot S_{M C}}{\delta}=6,5 \mathrm{mH} .
$$

The active resistance $r$ of the inductor magneting coil, wen an average length of the turn $l=0.5 \mathrm{~m}$, and in case of a copper ribbon of coil has a specific resistance $\rho_{W}=0.018(\Omega \cdot m) / \mathrm{mm}^{2}$ and cross-sectional area $S_{W}=40 \times 0.5=20 \mathrm{~mm}^{2}$ is:

$$
r=\frac{l_{c} \cdot n \cdot \rho_{W}}{S_{W}}=0.032 \Omega .
$$

The actual induction in the magnetic gap will be by $20 \%$ less due to dispersion [1], therefore, the gap induction will be $B=1.5 \mathrm{~T}$. Then an actual electromagnetic traction force $F_{E M}$ will be:

$$
F_{E M}=\frac{B^{2} \cdot S_{M C}}{2 \mu_{0}}=16580 \mathrm{~N}
$$

\section{The experimental technique and the results of comparison tests}

The experiments were carried out at a $100 \mathrm{~m}$ deep well with a known structure of a geological cross-section in the water basin of a test-and-training geophysical range (Minusinsk, Krasnoyarsk Territory). The MSK SGD-SLM "Gnome" seismic station was used with the SGD-SLM/G3 measuring acoustic to record the seismic signal level in the well. The acoustic probe consistently lowered to a depth of $50 \mathrm{~m}$ and $100 \mathrm{~m}$. The VEM-50 "Yenisei" water seismic source with a peak force of $500 \mathrm{kN}$ was used as a comparative sample. A series of 10 impacts was made for both seismic sources and for each position of the acoustic probe in the well.

An experimental verification of the calculated characteristics of the seismic source was carried out by recording the parameters of the force and pressure in water using by accelerometer and hydrophone. The accelerometer was located on the impact plate. The hydrophone was placed in water to a depth $h=1 \mathrm{~m}$ under the emitter plate (Fig. 2).

The measured acceleration magnitude of the emitter is $a=450 \mathrm{~m} / \mathrm{s}^{2}$. Then a total mass of the emitter (anchor + float) is $38 \mathrm{~kg}$ and the dimension of the dispersion plate is $60 \times 60 \mathrm{~cm}$, a scalar electromagnetic traction force $F_{E M}$ applied to the emitter is:

$$
F_{E M}=m \cdot a=17100 N .
$$

Moreover, a pressure applied by the base plate at the interface is:

$$
P_{E M}=\frac{F_{E M}}{S}=0.475 \mathrm{~kg} / \mathrm{cm}^{2} .
$$

The estimated values are in good agreement with a theoretical values of the force obtained according to the formula (5). A pressure value satisfies a limiting condition $P_{E M}<P_{\max }=1 \mathrm{~kg} / \mathrm{cm}^{2}$, causing parasitic cavitation processes in the emitter zone. 


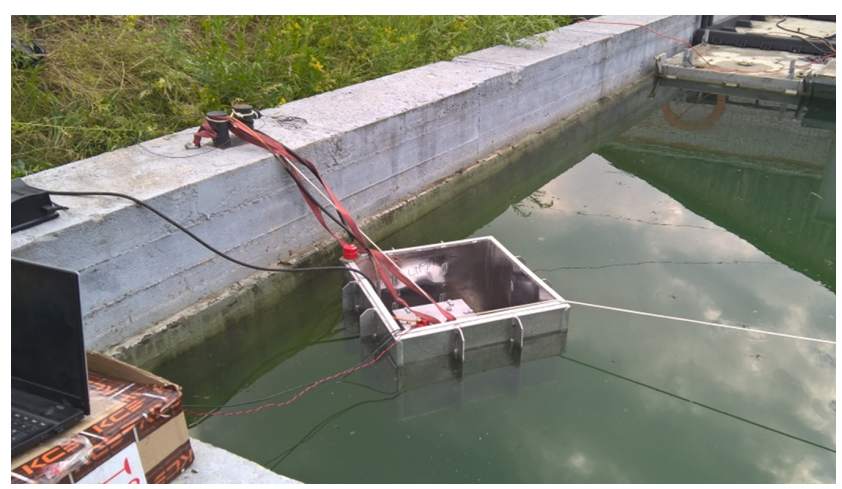

Fig. 2. EMSS model lowered in a test water tank

The impulse action is bipolar, as shown in the Fig. 3. On this basis it can be concluded that the choice of EMSS design was correct. The peak voltage of the positive half-wave on the hydrophone (the radiating plate moves upward), with a shock force of $F_{E M}=1 \mathrm{kN}$, is $U_{g}=700 \mathrm{mV}$. When a hydrophone sensitivity is $\gamma=39 \mu \mathrm{V} / \mathrm{Pa}$, the pressure $P_{g}$ at a depth of $1 \mathrm{~m}$ will be:

$$
P_{g}=\frac{U_{g}}{\gamma} \approx 18 \mathrm{kPa}=0.018 \mathrm{~kg} / \mathrm{cm}^{2}
$$

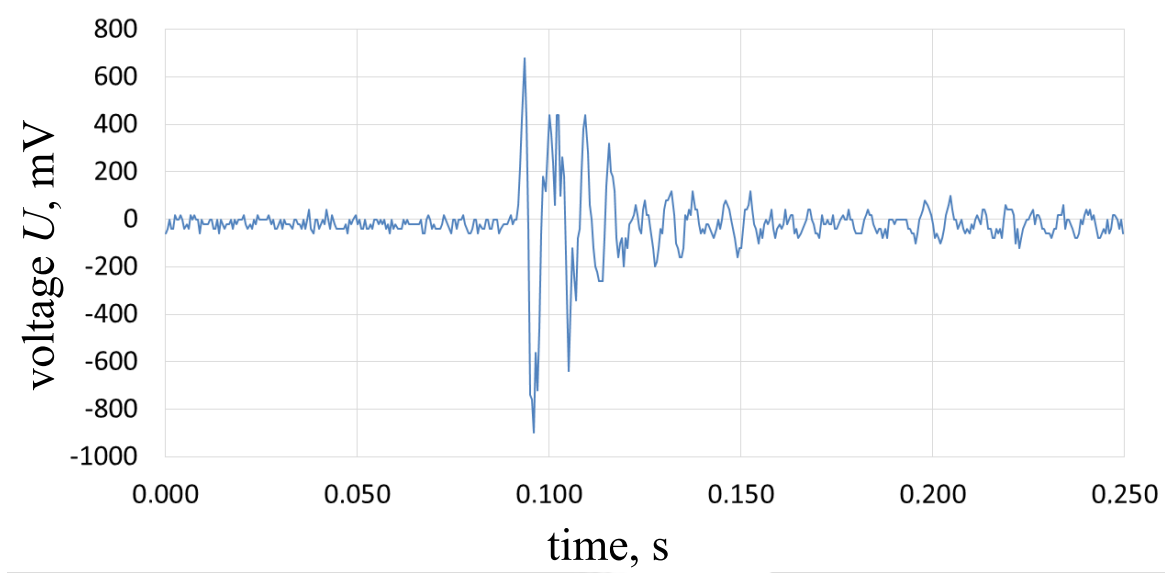

Fig. 3. The signal level recorded hydrophone

In Fig. 3 the residual oscillation is a multiplere reflection of the signal from the bottom and walls of the test water tank.

\section{Investigation of the seismic activity of EMSS during bipolar excitation of the medium}

The level of signals recorded in the well at a depth of $h=100 \mathrm{~m}$ from the VEM-50 and EMSS seismic sources located in the test water tank are chown in Figs. $4 \mathrm{a}, \mathrm{b}$. The results of the comparative tests are presented in the Tab. 1. There are levels of the recorded signals from the samples at different depths. 
Table 1. The voltage at the geophone output when testing VEM and EMSS

\begin{tabular}{|c|l|l|l|l|}
\hline \multirow{2}{*}{ Number of observations } & \multicolumn{2}{|c|}{ VEM amplitude signal, mV } & \multicolumn{2}{c|}{ EMSS amplitude signal, mV } \\
\cline { 2 - 5 } & $U_{\max 1}$ & $U_{\max 2}$ & $U_{\max 1}$ & $U_{\max 2}$ \\
\hline 1 & 0.0939 & 0.1085 & 0.0091 & 0.0140 \\
\hline 2 & 0.0948 & 0.1068 & 0.0083 & 0.0143 \\
\hline 3 & 0.0956 & 0.1060 & 0.0090 & 0.0143 \\
\hline 4 & 0.0946 & 0.1079 & 0.0099 & 0.0147 \\
\hline 5 & 0.0951 & 0.1093 & 0.0097 & 0.0150 \\
\hline 6 & 0.0939 & 0.1095 & 0.0083 & 0.0143 \\
\hline 7 & 0.0951 & 0.1092 & 0.0095 & 0.0123 \\
\hline 8 & 0.0920 & 0.1113 & 0.0097 & 0.0153 \\
\hline 9 & 0.0946 & 0.1119 & 0.0087 & 0.0130 \\
\hline 10 & 0.0937 & 0.1095 & 0.0095 & 0.0143 \\
\hline
\end{tabular}

An analysis of the signals received at a depth of 50 meters and 100 meters from the EMSS showed that the period of a bipolar pulse at both recording points has an identical pulse duration $\tau=16 \mathrm{~ms}$. Thus, the pulse duration does not change with increasing signal propagation depth. This indicates the effectiveness of using a bipolar seismic source. This effect may be due to a fact that in the VEM-50 source a "negative" half-wave is not emitted, and an impact energy is spent on a movement of the reactive mass. A negative half-wave was recorded by a seismic probe in the well and an accelerometer, which is fixed to the emitting surface. It is expected that it is formed in the medium due to the resonance properties of the source. Pulse duration is constant in EMSS, because the oscillation period is formed by a bipolar excitation signal. Theoretically, the advantages of bipolar excitation were investigated using an electric model of the geological medium. This medium is presented as a resonant oscillatory system [4].

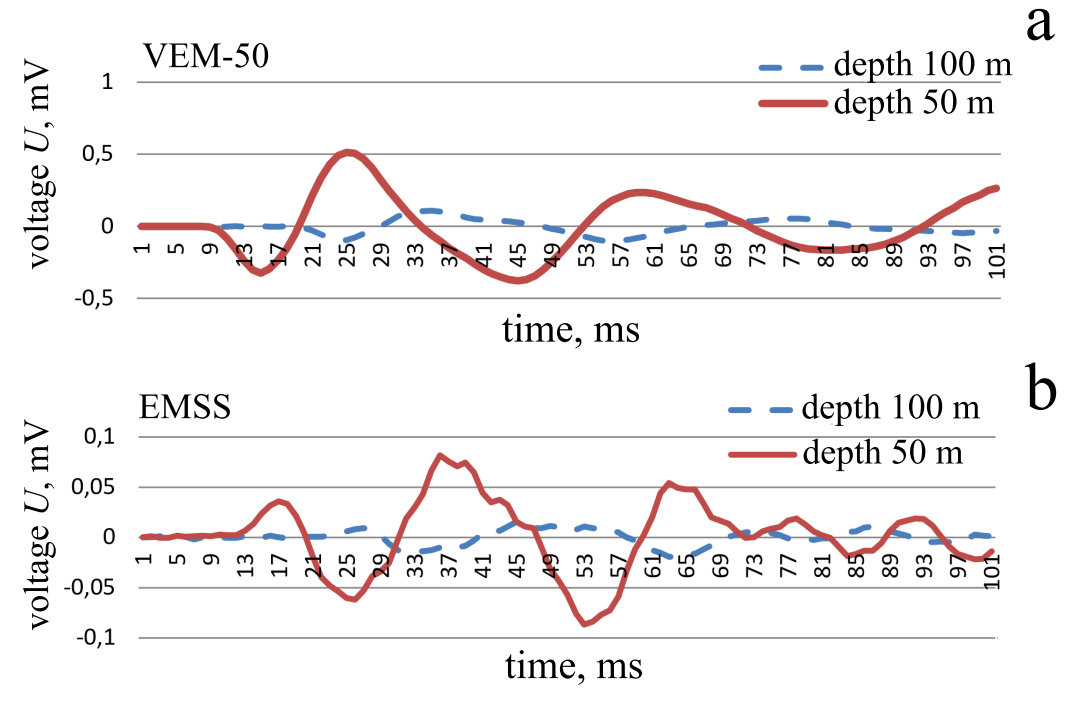

Fig. 4. The seismic signal recorded by the well acoustic sonde: a - from the VEM-50 seismic source; $\mathrm{b}$ - from the experimental model of the EMSS 
The amplitude values of signals at depths of 100 and $50 \mathrm{~m}$ are presented in the Tab. 1 in order to evaluate energy potential VEM-50 seismic source and EMSS as well their seismic efficiency. We have defined the concept of seismic efficiency of a seismic sources as the ratio of an acoustic pressure amplitude value at a specified space point to the action force of the emitter on a medium:

$$
\xi=\frac{P_{0}}{F_{E M}},
$$

where $P_{0}$ is acoustical pressure at a specified point in the geological environment. The pressure $P_{0}$ can be calculated by forming [5]:

where

$$
P_{0}=\rho \cdot c \cdot \vartheta_{0},
$$

$c$ is compressional velocity of elastic P-waves;

$\rho$ is density;

$\vartheta_{0}$ is vibrational particle velocity.

The estimated ratio for seismic efficiency can be obtained by calculating $\vartheta_{0}$ through the measured signal value at the well seismic probe:

$$
\xi=\frac{\rho \cdot c \cdot U_{a v}}{F_{E M} \cdot \gamma_{S}}
$$

where $\gamma_{S}$ is acoustic sonde sensitivity $\left[\frac{V \cdot c}{m}\right] ; U_{a v}$ is the average value of the signal level at the seismic station input circuit [V]. We determine the efficiency of EMSS in comparison with VEM-50 bu the formula:

$$
\frac{\xi_{E M S S}}{\xi_{V E M}}=\frac{F_{E M}^{V E M} \cdot U_{a v}^{E M S S}}{F_{E M}^{E M S S} \cdot U_{a v}^{V E M}} \approx 3.5 .
$$

Thus, the seismic efficiency of the EMSS is 3.5 times higher than the seismic efficiency of the VEM-50. Therefore, expected signal level for the VEM-50 will be provided when the force is:

$$
F_{E M}^{E M S S}=\frac{F_{E M}^{V E M}}{3.5}=142 k N,
$$

During synchronous operation of $N$ EMSS emitters will be:

$$
N \geqslant \frac{142 k N}{17.1 k N}=9 \text {. }
$$

Thus, a system configuration of the antenna array of synchronously operating emitters 9 $(3 \times 3)$ mounted on a floating platform will be equvalent of VEM-50. At the same time, the mass of the VEM-50 seismic source is approximately equal to $M_{V E M} \approx 5700 \mathrm{~kg}$, and the mass of one EMSS module complete with a reference float does not exceed $m=180 \mathrm{~kg}$. The experiment showed that the variant of a seismic source with an electromagnetic drive and bipolar excitation has higher energy efficiency and allows you to generate a signal with an identical amplitude to the VEM-50 source when the force acts on the medium 3 times less. In addition, EMSS has a higher probe pulse frequency.

According to the results of a series of 10 impacts, their amplitude identity is $\pm 5 \%$, which is sufficient reason to create a seismic source with good repeatability of the characteristics of seismic probe pulses. This parameter will ensure coherent integration mode in order to increase the signal-to-noise ratio without increasing the peak power of the seismic source. This will make it possible to reduce the negative acoustic effect on the environment when working in water areas and transition zone. Along with passive hydrocarbon search methods, similar studies have been actively conducted around the world in the last decade [6-9]. 


\section{Conclusion}

Analysis of the problem in the field of water seismic exploration works has revealed the advantage of EM sources over air-guns sources and explosions in terms of environmental friendliness and has made it possible to determine the disadvantages of pulsed EM seismic sources. Theoretical justification of effectiveness of using EMSS with bipolar excitation in comparison with seismic sources with an electromagnetic drive of the VEM-50 "Yenisei" series (SS VEM) is presented in article.

Investigational studies and comparative field tests of experimental models of EMSS and VEM50 seismic source represent essential scientific results. These results have confirmed that the choice of the proposed theoretical and mathematical models of sources functioning in the aquatic environment, their design, as well as the effectiveness of using bipolar excitation to ensure environmentally friendly and high-resolution seismic exploration works was made correctly works was made correctly. In particular, the development of a mathematical model of the source in an aquatic environment is issentional result in terms of particle. It describes the dependence of the movement of the base plate-emitter in a liquid under the action of an external driving force. The obtained results will be the basis for further research in the field of seismic signals based on a large database of $B \geqslant 1$ (orthonormal or noise-like signals).

The further studies include the completion of EMSS model of array configuration and comparative field tests at a geophysical training range and field of known geological section structure and comparative field test are carried out in comparison with pseudonoise signal seismic exploration and classical pulsed technology. Also research in the are of the propagation of unipolar, bipolar and M-sequence long pulses will be conducted.

Additionally, we plan to clarify the concept of added mass of water (medium), using a system of sensors based on accelerometers and hydrophones. The research of the ratios between the parameters of the added mass and the hydrodynamic indicators of water will allow us to choose the optimal size of the EMSS emitter.

The reported study was funded by RFBR and the government of Krasnoyarsk region according to the research project no. 18-45-242003. "Research and development of methods for distance increasing of the geological sounding by seismoacoustic pseudonoise orthonormal sequences signals". The authors also thank the Siberian Federal University and "Evenkiyageofizika" OJSC for their help in organizing field studies at the geophysical training and testing ground.

\section{References}

[1] O.B.Bull, Calculation methods for magnetic systems of electrical apparatus. Magnetic circuits, fields and the FEMM program. Textbook for universities in the specialty "Electrical and electronic devices" direction "Electrical Engineering, Electromechanics and Electrotechnology", Publishing House Academy, 2005 (in Russian).

[2] V.I.Bondarev, Seismic exploration, Ural State Mining University, 2007 (in Russian).

[3] V.V.Druzhinin, The magnetic properties of electrical steel, Publishing House: Energiya, 1974 (in Russian).

[4] G.Ya.Shaidurov, Yu.S.Vorontsov, D.S.Kudinov et al., Instruments and systems for exploration geophysics, 1(2013), no. 3, 97-101 (in Russian). 
[5] L.Bergman, Ultrasound and its application in science and technology, Publishing House of Foreign Literature, 1957 (in Russian).

[6] A.S.Belyakov, I.N.Didenkulov, A.D.Zhigalin et al., Geologiya i geofizika Yuga Rossii, 1(2017), no. 3, 5-12 (in Russian).

[7] B.Askeland, B.O.Ruud, H.Hobaek, R.Mjelde, Journal of Applied Geophysics, 67(2009), no. 1, 66-73. Doi: 10.1016/j.jappgeo.2008.09.011

[8] A.Brenders, J.Dellinger, SEG International Exposition and 87th Annual Meeting, 2016, 3992-3996. Doi: 10.1190/segam2016-13760222.1

[9] G.Y.Shaidurov, D.S.Kudinov, V.S.Potylitsyn et al., Russian Geology and Geophysics, 59(2018), no. 3, 566-570.

\title{
Физические основы формирования энергетически квазиоптимального импульсного сейсмоакустического воздействия для геофизических исследований в условиях мелководья и транзитных зон. Часть 2. Конструкция водного источника и результаты экспериментов
}

\author{
Данил С. Кудинов \\ Олег А. Майков \\ Сибирский федеральный университет \\ Красноярск, Российская Федерация \\ Павел В. Баландин \\ ООО "Эвенкиягеофизика" \\ Тюмень, Российская Федерация
}

\begin{abstract}
Аннотация. В статье дается научное обоснование разработанной конструкции сейсмоисточника (СИ). Оценивается эффективность двухполярного возбуждения водной среды СИ в сравнении с известными водными импульсными источниками серии «Енисей». Приводятся результаты моделирования влияния гидродинамического сопротивления среды СА воздействию, а также формирования «присоединенной массы». Результаты получены на основе разработанной математической модели движения излучающей поверхности. На основе проведенных опытных работ сделан сравнительный анализ энергетической эффективности работы макета СИ и серийного образца водного СИ ВЭМ-50 модельного ряда «Енисей». Экспериментальные результаты получены на геофизической скважине учебно-испытательного полигона Сибирского федерального университета.
\end{abstract}

Ключевые слова: сейсмоисточник, сейсмоакустика, псевдослучайная последовательность, мелководье, транзитная зона. 